\title{
Three-dimensional morphology of rigid structures as a tool for taxonomic studies of Dactylogyridae (Monogenea)
}

\author{
María A. Rossin $^{1}$ • Pablo N. De Francesco ${ }^{2}$ Juan T. Timi ${ }^{1}$
}

Received: 8 June 2017 / Accepted: 10 August 2017

(C) Springer-Verlag GmbH Germany 2017

\begin{abstract}
Dactylogyridae is overwhelmingly the most abundant and diverse taxon among monogeneans in continental waters of South America. Their small body size requires considerable sampling effort and training for collecting and identifying the worms from the gills, skin, nasal cavities, and other microhabitats. Indeed, diagnostic characteristics as sclerites and male copulatory complex are generally less than $100-\mu \mathrm{m}$ long and are essential for taxonomic description and identification of species. Here, a combination of simple and routine methods for three-dimensional morphological studies on hard structures is proposed for dactylogirids: SDS treatment for clarification of specimens and enzymatic digestion with proteinase $\mathrm{K}$ for freeing sclerotized structures, followed by laser confocal microscopy. This method is applicable to fresh or fixed specimens and does not require staining or dehydration. Indeed, stable autofluorescence emission is detectable at $500-530 \mathrm{~nm}$ for bars, anchors, and male copulatory
\end{abstract}

Electronic supplementary material The online version of this article (doi:10.1007/s00436-017-5591-y) contains supplementary material, which is available to authorized users.

María A. Rossin

mrossin@mdp.edu.ar

1 Laboratorio de Ictioparasitología, Instituto de Investigaciones Marinas y Costeras (IIMIyC), Facultad de Ciencias Exactas y Naturales, Universidad Nacional de Mar del Plata-Consejo Nacional de Investigaciones Científicas y Técnicas (CONICET) Funes 3350, (7600) Mar del Plata, Argentina

2 Laboratorio de Neurofisiología, Instituto Multidisciplinario de Biología Celular (IMBICE), Consejo Nacional de Investigaciones Científicas y Técnicas (CONICET) - Universidad Nacional de La Plata - Comisión de Investigaciones Científicas de la Provincia de Buenos Aires (CIC-PBA), Calle 526 y Cno. Gral. Belgrano, La Plata, Argentina complex when excited by argon laser. Advantages of this protocol over previous methodologies for taking laser confocal images are discussed. Open access software for image processing was used for three-dimensional reconstruction of sclerotized structures generating models and full $360^{\circ}$ rotation videos.

Keywords Monogenea $\cdot$ SDS treatment $\cdot$ Proteinase K treatment $\cdot$ Laser confocal images $\cdot$ Autofluorescence . Three-dimensional reconstruction

\section{Introduction}

Monogeneans are a diverse group in terms of species richness, being also highly variable in their morphology and ecology (Poulin 2002). This group of organisms has a broad spectrum of host species, but individual species show relatively high levels of host specificity (Kritsky et al. 1996a, b, 1997a, b). Among monogeneans, the family Dactylogyridae is overwhelmingly the most abundant taxon in continental waters of South America (Thatcher 2006). Despite the efforts made by taxonomists, it is estimated that only less than $3 \%$ of the monogeneans parasitizing freshwater fishes are known in this region (Thatcher 2006). This fact can be a consequence of their small body size $(<1 \mathrm{~mm})$, which requires a higher sampling effort and considerable training for collecting and identifying the worms from the gills, skin, nasal cavities, and other microhabitats. In addition, the scarce numbers of taxonomists in the field, the complex morphology of dactylogyrids, and their confusing classification have led to many incorrect or erroneous taxonomic determinations.

The identification of dactylogyrids is based primarily on their sclerotized structures, such as hooks, anchors, bars, male copulatory organ (MCO), accessory piece, and, in some cases, 
vagina, but internal soft structures (male and female reproductive organs) are also fundamental for diagnoses in many genera.

Three main problems arise when taxonomy studies are conducted in this group of parasites. First, to obtain a clear view of minute diagnostic structures, normally obscured by surrounding tissues. Indeed, sclerites and male copulatory complex are generally less than $100-\mu \mathrm{m}$ long and are essential for taxonomic identification. Normally, Hoyer and Gray and Wess have been widely used as clearing and mounting media, whereas ammonium picrate-glycerin has been also applied as a fixative and clearing agent (Malmberg 1957; Lim and Furtado 1986). More recently, Wong et al. (2006) proposed the use of sodium dodecyl sulfate (SDS) which makes parasitic worms quickly transparent.

The second problem lies in that these sclerotized structures are immersed in soft internal tissues hindering the identification of their limits and, consequently, of their real shape under optical microscopy. As a solution to the inability to make a complete visualization of these internal structures, some researchers isolated them from soft tissues either by sonication or, more commonly, by enzymatic digestion followed by observation under scanning electron microscopy (SEM) following conventional protocols (e.g., Mo and Appleby 1990; Shinn et al. 1993; Harris et al. 1999; Dos Santos and Avenant-Oldewage 2015; Fannes et al. 2015).

Finally, although these sclerotized structures can be cleaned, isolated and individually visualized by SEM, a third difficulty to be resolved is the three-dimensionality of their shape. The sclerotized structures of dactylogyrid, especially the male copulatory complex, have complicated threedimensional shapes, where ventral and dorsal surfaces may easily be misinterpreted and erroneously combined in a twodimensional illustration or microphotograph obtained by a light microscope. Inadequate morphological studies and misinterpretations of three-dimensional shapes of these structures repeatedly result in morphologic, taxonomic, and systematic errors that greatly hinder the evolution of the knowledge in the group (Thatcher 2006). With the advent of laser scanning confocal fluorescence microscopy (LSCFM), some researchers have explored the possibility of applying this methodology to visualize haptoral sclerites and male copulatory complex of some groups of monogeneans, including the tridimensionality of its forms in the descriptions (Galli et al. 2006, 2007; Garcia-Vásquez et al. 2012). These authors proposed the use of LSCFM for specimens fixed in formalin, stained with different staining solutions, and previous treatment with $\mathrm{NaOH}$, dehydrated, cleared, and mounted in Canada balsam. This methodology follows long and tedious protocols, requiring several steps and employing many reagents, such as cromotropes, colorants, cleaning agents, dehydrating solutions, and mounting media. Additionally, a relatively high number of specimens are often required for a process that can take several days. Furthermore, successful results depend on the stage of conservation of the specimens, the fixatives used, and the histological characteristics of the studied organs or species. Also, the use of $\mathrm{NaOH}$ can, in some cases, distort the morphology of hooks (Garcia-Vásquez et al. 2012). In addition, the presence of soft tissues surrounding the hard structures results in considerable background noise in the images obtained by LSCFM.

The aim of this work is to propose a fast, easy, and routine method for studying three-dimensionality of sclerotized structures of dactylogyrid monogeneans. The detailed description of the two-dimensional and three-dimensional shape of these structures will provide greater certainty and detail, constituting a useful ancillary tool for taxonomic studies.

\section{Materials and methods}

\section{The specimen's collection and preservation}

Two freshwater dactylogyrid species were collected, namely Rhinoxenus piranhus Kritsky et al., 1988, parasite of the nasal cavity of Pygocentrus nattereri Kner, 1988 (Characidae) from the Paraná River and its tributary, the Colastine River $\left(31^{\circ} 36^{\prime}\right.$ $51^{\prime \prime} \mathrm{S}, 60^{\circ} 32^{\prime} 19 \mathrm{~W}$ ), Santa Fe Province, Argentina, and Characithecium chascomusensis (Suriano, 1981) Rossin and Timi 2014, from the gills of Oligosarcus jenynsii Günther, 1864 (Characidae) from Chascomus Lake $\left(35^{\circ} 37^{\prime} \mathrm{S}, 58^{\circ}\right.$ 04' W), Buenos Aires Province, Argentina.

A set of monogeneans was fixed in $70 \%$ ethanol and then stored at $-20{ }^{\circ} \mathrm{C}$ until required; a second set was fixed in 5\% neutral buffered formalin.

\section{Light microscopy}

Two methods were used and evaluated, SDS treatment and enzymatic digestion applied to 10 specimens of each species.

SDS treatment For morphological two-dimensional study under light microscopy, specimens fixed in formalin $4 \%$ and ethanol $70 \%$ were individually placed on a glass slide in a droplet of distilled water $(\sim 3 \mu \mathrm{l})$ using a needle and covered with a glass coverslip $(48 \times 48 \mathrm{~mm})$. Under a microscope at a low resolution, and following the protocol of Wong et al. (2006), SDS $10 \%$ was added in a side of coverslip using a Pasteur pipette and the excess of liquid was absorbed carefully with the aid of tissue paper on the opposite side of the coverslip. This action was repeated until the specimen was completely embedded in the SDS solution.

Images of the opistohaptoral hard parts and of the male copulatory complex were captured at magnifications of $\times 40$ and $\times 100$ (oil immersion) using Leica Application Suite 
Fig. 1 Light micrographs. a, b SDS treatment of Rhinoxenus piranhus Kritsky et al., 1988, specimens. a Male copulatory complex (ventral view). b Anchor roots and ventral bar (ventral view, asterisk indicates muscle that joins both anchors). c, d PK treatment of $R$. piranhus specimens fixed in formalin. c Male copulatory complex (ventral view). d Anchor and ventral bar (ventral view). $\mathbf{e}-\mathbf{i}$ PK treatment of Characithecium

chascomusensis (Suriano, 1981) specimens fixed in alcohol. e Male copulatory complex (ventral view). f Ventral anchor (ventral view). g Dorsal anchor (ventral view). h Ventral bar (ventral view). i Dorsal bar (ventral view). Scale bars: a-d $50 \mu \mathrm{m} ; \mathbf{e ,} \mathbf{f} 10 \mu \mathrm{m}$
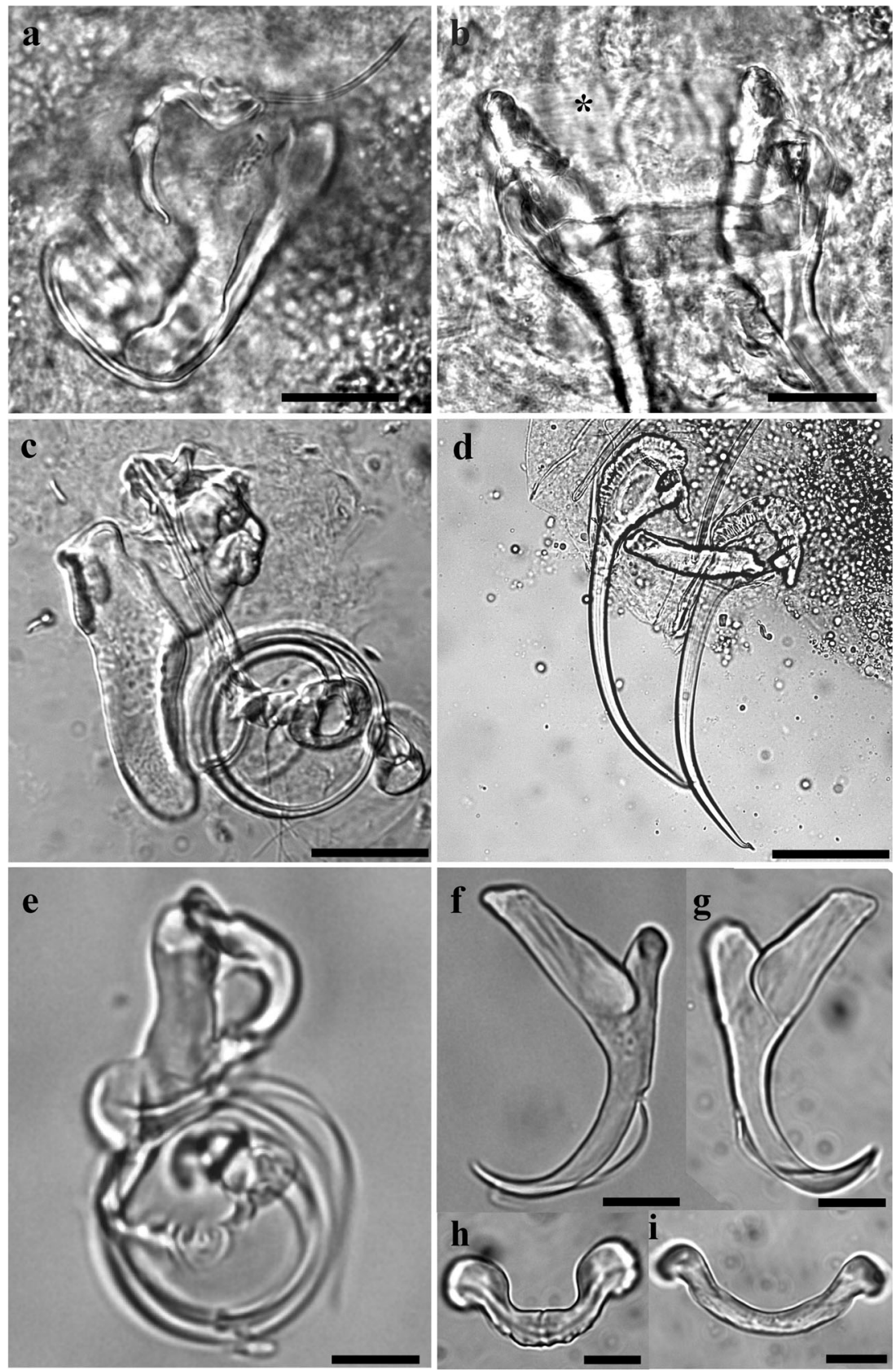

(LAS) Leica Microscope Software and a Leica DFC 295 digital camera mounted on a Leica DM 2500 compound microscope, using a $\times 0.55$ interfacing lens.

Enzymatic digestion The same specimens used by twodimensional studies were used for three-dimensional studies; only special care must be taken if specimens were previously fixed in formalin, which must be thoroughly rinsed in tap water for several hours (at least $3 \mathrm{~h}$ ) before SDS treatment. Subsequently, specimens embedded in SDS were subjected to full-enzymatic digestion with proteinase $\mathrm{K}$ in order to obtain tissue-free sclerites (Fannes et al. 2015). Additionally, specimens preserved in alcohol $70 \%$ were also digested without previous SDS treatment. The enzymatic digestion solution was prepared by adding proteinase $\mathrm{K}$ solution to an equal volume (1:1) of ATL lysis buffer (DNeasy® Blood and Tissue kit, Qiagen) (Fannes et al. 2015). This solution was pipetted up and down several times to ensure complete mixing. Next, $3 \mu l$ of the freshly made digestion solution were added to the specimen on one side of a cover glass. Simultaneously, on the opposite side of the cover glass, the excess of liquid (SDS or alcohol 70\%) was carefully removed by tissue paper until totally replaced by the digestion solution $(\mathrm{SDS}+\mathrm{ATL})$. 
The progress of the digestion was continuously monitored under a magnification of $\times 40$. Specimens fixed in formalin and rinsed in water may require the use of a laboratory oven at $45-60^{\circ}$, and the progress of digestion must be checked under a microscope. Tissue digestion was stopped by the addition of $2.5 \mu \mathrm{l}$ of formalin. Images of the opistohaptoral hard parts and the male copulatory complex were captured as described for SDS treatment.

\section{Laser scanning confocal fluorescence microscopy}

Semi-permanent mounts were made for one specimen of each species by adding nail varnish to the borders of the coverslip after stopping enzymatic digestion. The position of hard parts on the slide was pointed with a permanent marker to be easily localized in the LSCFM.

Hard parts were examined using a Nikon C1 SiR LSCFM. Confocal Z-series of images were collected using a PL APO $\times 40$ (numerical aperture: 1.3) or PL APO $\times 60$ (numerical aperture: 1.4) oil immersion objective and digitalized by the EZ-C1 3.90 Free Viewer software. A krypton-argon laser was used for fluorescence excitation at $488 \mathrm{~nm}$; fluorescence emission was detected at 515/30 nm. Images were collected at 16 bits with $512 \times 512$ pixels per frame. The width of the scanned field varied between 30 and $140 \mu \mathrm{m}$.

\section{Three-dimensional reconstructions}

Examinations as well as image pre- and post-processing steps of Z-series from sclerotized structures were conducted using the open source software Fiji (Schindelin et al. 2012). Stacks that presented a significant attenuation associated with increasing imaging depth were corrected with a linearly or exponentially increasing factor along the $z$-axis. Stacks were then deconvolved using the CMLE algorithm with the software Huygens (SVI, Hilversum, Netherlands), which provided a major improvement in the signal-to-noise ratio of the confocal stack as well as a modest increase in resolution. Afterward, the brightness and contrast of the stacks were adjusted in Fiji, and three-dimensional iso-surface reconstructions of the pieces were obtained with the three-dimensional viewer plug-in. A resampling factor of two was always used, and the threshold value was adjusted to obtain the desired level of detail. Finally, these three-dimensional models were processed in the open source software Blender (www.blender. org). The surfaces corresponding to objects of interest were isolated from surrounding debris, and evident artifacts due to fusion with adjacent debris were corrected by editing the model mesh. The location of these edited patches is clearly marked in purple in the supplementary videos. For the final presentation, a smoothing filter (factor: 0.5, repeats: 10) was applied to the meshes, and three-dimensional renders were
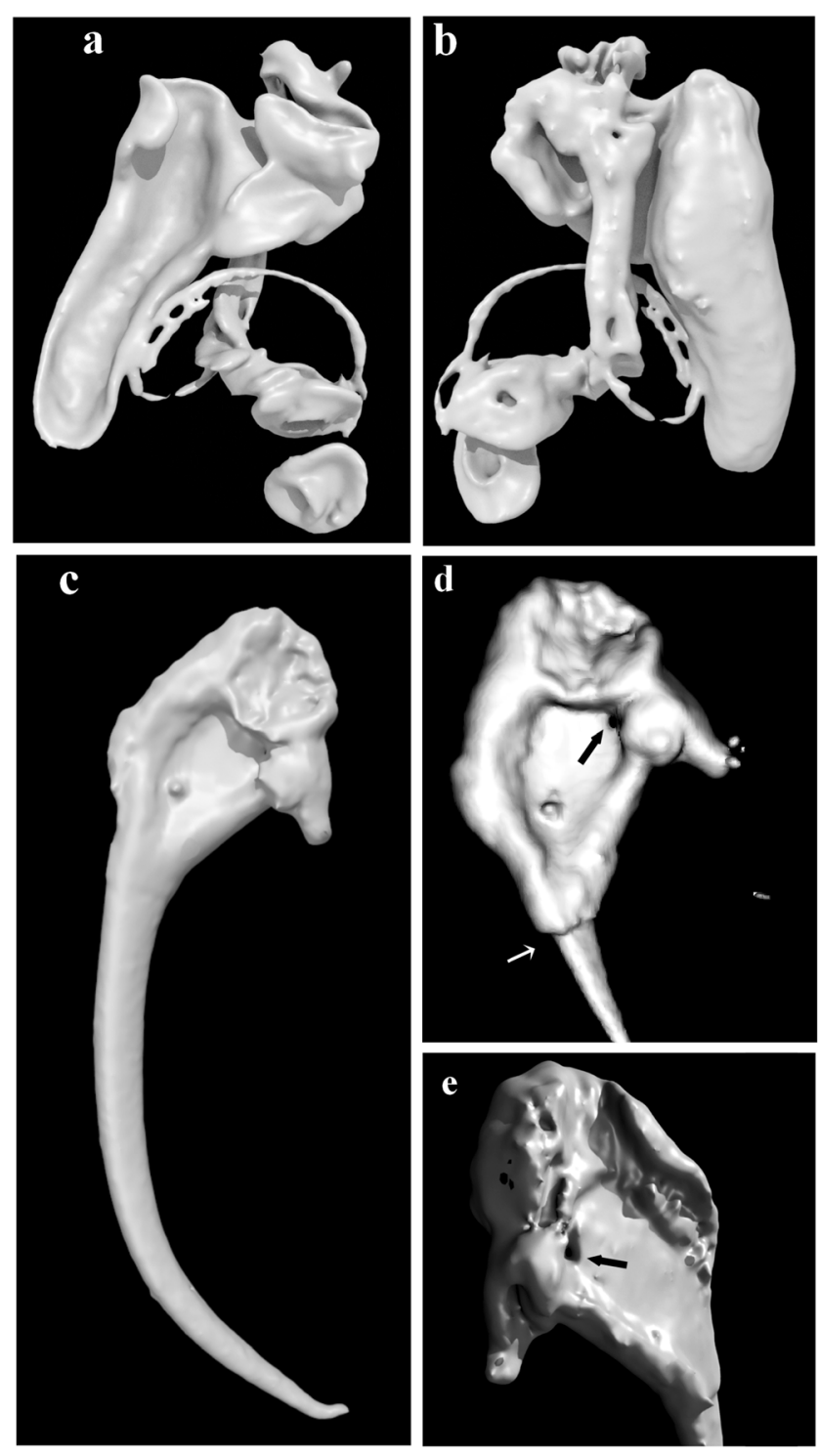

Fig. 2 Three-dimensional reconstruction of sclerotized structures of Rhinoxenus piranhus Kritsky et al., 1988. a Male copulatory complex (ventral view). b Male copulatory complex (dorsal view). c Ventral anchor (ventral view). d Anchor root (ventral view, black arrow indicates a hole present in the base of root, white arrow indicates limit of shaft inside of body). e Anchor root (dorsal view, black arrow indicates a hole present in the base of root)

produced. Full $360^{\circ}$ rotation videos of the models were also produced and exported in AVI format.

\section{Ethical approval}

The research has been conducted according to Argentine laws. All applicable institutional, national, and international guidelines for the care and use of animals were followed. Permit for fishing was provided by the Ministerio de Asuntos Agrarios de la Provincia de Buenos Aires, Argentina (Disposición 164, August 23, 2012). 
Fig. 3 Three-dimensional reconstruction of sclerotized structures of Characithecium chascomusensis (Suriano, 1981). a Male copulatory complex (ventral view). b Detail of ligament junction of accessory piece in ventral view. c Male copulatory complex (dorsal view). d Detail of ligament junction of accessory piece in dorsal view. e Ventral bar (ventral view). f Ventral bar (dorsal view)
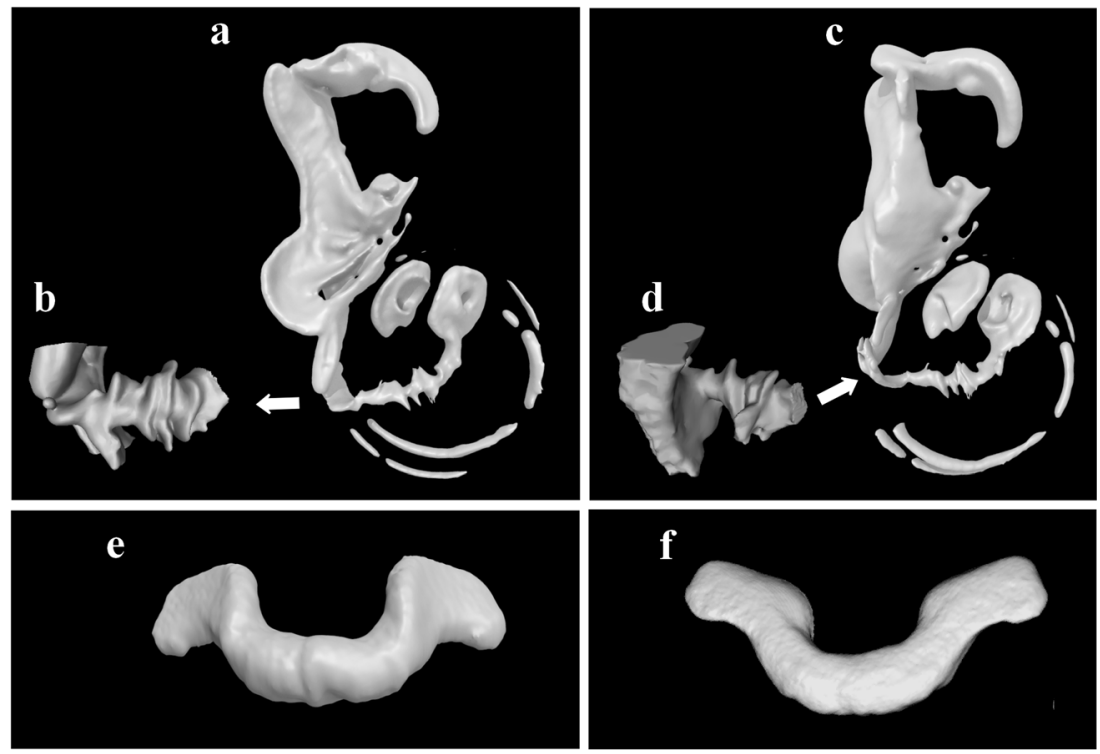

\section{Results}

\section{Light microscopy}

After a few minutes, SDS-treated specimens started clearing, soft tissues became transparent, and sclerotized structures could be identified easily. Their borders, however, are often obscured by soft tissues and because structures overlap in a natural position (i.e., anchors and bars, $\mathrm{MCO}$, and accessory piece). The same results were obtained for both formalin and alcohol fixed specimens (Fig. 1a, b). On the other hand, the enzymatic digestion allowed freeing the hooks, anchors, accessory piece, and MCO from the surrounding tissue for both formalin and alcohol fixed specimens (Fig. 1c, d). The time required for digestion depended mainly on the body size and the fixative used. While alcohol-fixed specimens are digested in a few minutes (Fig. 1e, f), the formalin-fixed specimens should be previously washed in distilled water to achieve total digestion with proteinase $\mathrm{K}$, in this case, the process can take from a few minutes to hours. In some cases, when the specimens were fixed for a long time in formalin, we recommend an overnight digestion at $45-60^{\circ}$ (Fig. 1c, d). After a total digestion, detailed images of hard structures can be observed individually (Fig. 1e-i). Additionally, the proteinase K solution provides a viscous medium that prevents flattening of structures and allows their rotation by gently applying light pressure on the borders of the coverslip, favoring their observation from different perspectives to gain insight into the three-dimensional shape of these structures.

\section{Laser scanning confocal fluorescence microscopy}

Autofluorescence was detected in bars, anchors, and male copulatory complex when it was excited at $488 \mathrm{~nm}$ by argon laser (Supplementary Figs. 1, 2). A stable fluorescence emission was detected at 500-530. Only the MCO showed a low level of detectable fluorescence; however, its reel-shaped base and the ligament that articulates with the accessory piece showed a high and stable level of fluorescence (Supplementary Figs. 1a, c, 2a, c). Stable fluoresce was also observed for anchors and bars, anchor roots presenting the maximum levels, whereas the points and shanks showed the lower levels of fluorescence emitted (Supplementary Figs. 1b, $\mathrm{d}, \mathrm{e}, 2 \mathrm{~b}, \mathrm{~d}$, and e). Sclerotized structures embedded in the proteinase $\mathrm{K}$ solution showed optimal autofluorescence when compared with other mounting media, and a minimum background was detected. A step size (section thickness) ranging from 0.2 to $0.3 \mu \mathrm{m}$ was chosen and an average of $80-100$ section images was obtained for each sample, depending on the size and thickness of each piece $(20-30 \mu \mathrm{m}$ in the $z$-axis depth).

\section{Three-dimensional reconstructions}

From the set of images obtained with LSCFM, it was possible to reconstruct the sclerotized structures and build models for both species trough readily available software. A threedimensional reconstruction (3-DR) of the MCO was not possible because of the low fluorescence emission of this structure in both species. Despite this, 3-DR was possible of the accessory piece, ligament, and base of $\mathrm{MCO}$, which allowed obtaining a high level of morphological detail (Figs. 2a, b and 3a-d). Ventral bar and anchors were successfully rebuilt, despite anchors point showed low fluorescent emission (Figs. 2c-e and 3e, f, Supplementary Movies 2, 4-5). Supplementary movies of three-dimensional models in $360^{\circ}$ of the male copulatory complex, the anchors, and the ventral bar of $R$. piranhus and $C$. chascomusensis allowed a better 
interpretation of their shape in both dorsal and ventral views (Supplementary Movies 1-5).

\section{Discussion}

Laser scanning confocal fluorescence microscopy (LSCFM) has become an exciting new instrument because of its increased resolution over conventional wide-field microscopy and its high performance for three-dimensional optical sectioning. Although LSCFM has been used extensively in cell biology, few applications have been reported in studies of invertebrates (Bulantová et al. 2011; Yoon et al. 2013; Petrov et al. 2015; Michels and Gorb 2012; Michels et al. 2016). Its application to the study of rigid structures of monogeneans represents an important advance for the systematics of this taxon (Galli et al. 2006, 2007; Garcia-Vásquez et al. 2012), although supposes that the application of tedious protocols and desirable results is not always achieved.

The protocol proposed here has the following advantages over previous methodologies: (1) it can be performed for a single specimen, fresh or fixed in either formalin or alcohol; (2) the process can take only few minutes and does not require the use of staining solutions nor dehydration processes that can affect the morphology of hard parts; (3) the use of SDS as a rapid cleaning agent allows studying specimens before being digested, so the visualization and subsequent interpretation of the spatial orientation (ventral or dorsal, anterior or posterior) in their natural position result in better line drawings of isolated structures; (4) total digestion of the soft parts avoids the background noise (weak autofluorescence emission) caused by these tissues; (5) the scans reveal details that are difficult or impossible to see with light microscopy allowing obtaining accurate three-dimensional constructions and model images of these structures; (6) after stopping digestion, specimens can be maintained in the proteinase $\mathrm{K}$ solution which provides a sufficiently dense medium to prevent crushing of the hard parts and allow their rotation and observation from different perspectives; (7) proteinase $\mathrm{K}$ as a mounting medium does not emit signal detectable by LSCFM; and (8) the use of nail varnish allows mounting semi-permanent slides.

LSCFM, however, is not without disadvantages, as it can introduce some artifacts as distortions in the $z$-axis (Klaus et al. 2003). Nevertheless, a comparison of LSCFM images of monogenean sclerites with the respective optical microscope images and 3-DR reconstructions suggests that the axial distortion is minimal or imperceptible, such as has been observed by Galli et al. (2006). Another disadvantage of this method is that permanent preparations cannot be obtained in order to be deposited in museums, although if these semipermanent slides are properly sheltered, they can remain for a long time without being altered. On the other hand, the high quality and representativeness of digital microphotographs, Zstacks, and three-dimensional models obtained with this methodology constitute useful additional material for the deposition of type specimens.

In contrast to the results obtained by Galli et al. (2007), who did not observe autofluorescence of the hard parts of monogeneans, including dactylogyrids, our results showed the opposite, with anchors, bars, and male copulatory complex showing detectable and stable levels of autofluorescence emissions. This relevant result justifies the proposal of this simple methodology as a routine work to obtain high-quality morphological information essential for diagnoses and descriptions of dactylogyrids: especially taking into account that thousands of species remain undescribed and that several congeneric species, normally very similar each other, are often syntopically found on the same host individual (Boeger and Kritsky 1988; da Graça et al. 2013; Rossin and Timi 2014; Moreira et al. 2015), requiring, therefore, a high degree of detail in specific identifications.

Acknowledgements The authors wish to thank to Dr. Pablo Scarabotti, Instituto Nacional de Limnologia (INALI), and Lic. Manuel Irigoitia, Instituto de Investigaciones Marinas y Costeras (IIMyC), for providing fish samples of Pygocentrus nattereri from Paraná River. We also like to thank Dra. M. Daniela Villamonte and Lic. Viviana Daniel for the support obtaining images from the Nikon $\mathrm{C} 1 \mathrm{SiR}$ confocal microscope and the anonymous reviewer for your suggestions that improved the quality of our work. Finding: this work was supported by the Agencia Nacional de Promoción Científica y Tecnológica (grant number ANPCYT-PICT 2015 $\mathrm{N}^{\circ}$ 2013); CONICET (grant number CONICET-PIP $\mathrm{N}^{\circ} 112$ 20150100973); and Universidad Nacional de Mar del Plata, Argentina (grant number UNMdP-EXA 869/16).

Compliance with ethical standards The research has been conducted according to Argentine laws. All applicable institutional, national, and international guidelines for the care and use of animals were followed. Permit for fishing was provided by the Ministerio de Asuntos Agrarios de la Provincia de Buenos Aires, Argentina (Disposición 164, August 23, 2012).

\section{References}

Boeger WA, Kritsky DC (1988) Neotropical Monogenoidea. 12. Dactylogyridae from Serrasalmus nattereri (Cypriniformes, Serrasalmidae) and aspects of their morphologic variation and distribution in the Brazilian Amazon. Proc Helminthol Soc Wash 55: $188-213$

Bulantová J, Chanová M, Houžvičková L, Horák P (2011) Trichobilharzia regenti (Digenea: Schistosomatidae): changes of body wall musculature during the development from miracidium to adult worm. Micron 42:47-54. doi:10.1016/j.micron.2010.08. 003

Dos Santos QM, Avenant-Oldewage A (2015) Soft tissue digestion of Paradiplozoon vaalense for SEM of sclerites and simultaneous molecular analysis. J Parasitol 101:94-97. doi:10.1645/14-521.1

Fannes W, Vanhove MP, Huyse T, Paladini G (2015) A scanning electron microscope technique for studying the sclerites of Cichlidogyrus. Parasitol Res 114:2031-2034. doi:10.1007/s00436-015-4446-7 
Galli P, Strona G, Villa AM, Benzoni F, Stefani F, Doglia SM, Kritsky D (2006) Three-dimensional imaging of monogenoidean sclerites by confocal laser scanning microscopy. J Parasitol 92:395-399. doi:10. 1645/GE-3544RN.1

Galli P, Strona G, Villa AM, Benzoni F, Stefani F, Doglia SM, Kritsky DC (2007) Two-dimensional versus three-dimensional morphometry of monogenoidean sclerites. Int J Parasitol 37:449-456. doi:10.1016/j. ijpara

Garcia-Vásquez A, Shinn AP, Bron JE (2012) Development of a light microscopy stain for the sclerites of Gyrodactylus von Nordmann, 1832 (Monogenea) and related genera. Parasitol Res 110:16391648. doi:10.1007/s00436-011-2675-y

da Graça RJ, Ueda BH, Oda FH, Takemoto RM (2013) Monogenea (Platyhelminthes) parasites from the gills of Hoplias aff. malabaricus (Bloch, 1794) (Pisces: Erythrinidae) in the Upper Paraná River Floodplain, states of Paraná and Mato Grosso do Sul, Brazil. Check List 9:1484-1487 ISSN 1809-127X

Harris PD, Cable J, Tinsley RC, Lazarus CM (1999) Combined ribosomal DNA and morphological analysis of individual gyrodactylid monogeneans. J Parasitol 85:188-191 198.101.234.89. 7

Klaus AV, Kulasekera VL, Schawaroch V (2003) Three-dimensional visualization of insect morphology using confocal laser scanning microscopy. J Microsc 212:107-121. doi:10.1046/j.1365-2818.2003. 01235.x

Kritsky DC, Van Every LR, Boeger WA (1996a) Neotropical Monogenoidea. 27. Two new species of Telethecium gen. n. from the nasal cavities of Central Amazonian fishes and a redescription of Kritskyia moraveci Kohn, 1990 (Dactylogyridae, Ancyrocephalinae). J Helminthol Soc Wash 63:35-41

Kritsky DC, Boeger WA, Jegu M (1996b) Neotropical Monogenoidea. 28. Ancyrocephalinae (Dactylogyridae) of piranha and their relatives (Teleostei, Serrasalmidae) from Brazil and French Guiana: species of Notozothecium Boeger and Kritsky, 1988, and Mymarothecium gen. N. J Helminthol Soc Wash 63:153-175

Kritsky DC, Boeger WA, Jegu M (1997a) Neotropical Monogenoidea. 29. Ancyrocephalinae (Dactylogyridae) of piranha and their relatives (Teleostei, Serrasalmidae) from Brazil: species of Amphithecium Boeger and Kritsky, 1988, Heterothecium gen. n. and Pithanothecium gen. n. J Helminthol Soc Wash 64:25-54

Kritsky DC, Boeger WA, Jegu M (1997b) Neotropical Monogenoidea. 30. Ancyrocephalinae (Dactylogyridae) of piranha and their relatives (Teleostei, Serrasalmidae) from Brazil: species of Calpidothecium gen. n., Calpidothecioides gen. n., Odothecium gen. n., and Notothecioides gen. n. J Helminthol Soc Wash 64: 208-218

Lim LHS, Furtado JI (1986) Five new species of ancylodiscoidins (Monogenea: Ancylodiscoidinae) from Notopterus chitala
(Hamilton) and Notopterus notopterus (Pallas) in Peninsular Malaysia. Folia Parasitol 33:315-325

Malmberg G (1957) Om förekomsten av Gyrodactylus påsvenska fiskar. Särtryck ur Skrifter utgivna av Södra Sveriges Fiskeriförening Ársskrift 1956:19-76

Michels J, Gorb SN (2012) Detailed three-dimensional visualization of resilin in the exoskeleton of arthropods using confocal laser scanning microscopy. J Microsc 245:1-16. doi:10.1111/j.1365-2818. 2011.03523.x

Michels J, Appel E, Gorb SN (2016) Functional diversity of resilin in Arthropoda. Beilstein J Nanotechnol 7:1241-1259. doi:10.3762/ bjnano.7.115

Mo TA, Appleby C (1990) A special technique for studying haptoral sclerites of monogeneans. Syst Parasitol 17:103-108. doi:10.1007/ BF00009797

Moreira J, Scholz T, Luque JL (2015) First data on the parasites of Hoplias aimara (Characiformes): description of two new species of gill monogeneans (Dactylogyridae). Acta Parasitol 60:254-260. doi:10.1515/ap-2015-0036

Petrov A, Papyuk M, Dmitrieva EV, Gerasev PI (2015) Architecture of haptoral musculature in three species of Ligophorus (Monogenea, Ancyrocephalidae). Proc ZIN 319:244-256. doi:10.5281/zenodo. 19833

Poulin R (2002) The evolution of monogenean diversity. Int J Parasitol 32:245-254. doi:10.1016/S0020-7519(01)00329-0

Rossin MA, Timi JT (2014) Dactylogyrid monogeneans parasitic on the Neotropical fish Oligosarcus jenynsii (Pisces: Characidae) from the Pampasic region, Argentina; with the emendation of the genus Characithecium. Zootaxa 3893:382-396. doi:10.11646/zootaxa. 3893.3.4

Schindelin J, Arganda-Carreras I, Frise E, Kaynig V, Longair M, Pietzsch $\mathrm{T}$ (2012) Fiji: an open-source platform for biological-image analysis. Nat Methods 9:676-682. doi:10.1038/nmeth.2019

Shinn AP, Gibson DI, Sommerville C (1993) An SEM study of the haptoral sclerites of the genus Gyrodactylus Nordmann, 1832 (Monogenea) following extraction by digestion and sonication techniques. Syst Parasitol 25:135-144. doi:10.1007/BF00009983

Thatcher VE (2006) Amazon fish parasites, 2nd edn. Pensoft, Sofia, p 509

Wong WL, Tan WB, Lim LHS (2006) Sodium dodecyl sulphate as a rapid clearing agent for studying the hard parts of monogeneans and nematodes. J Helminthol 80:87-90. doi:10.1079/JOH2005320

Yoon GH, Jufaili SA, Freeman MA, Bron JE, Paladini G, Shinn AP (2013) Omanicotyle heterospina n. gen. et n. comb. (Monogenea: Microcotylidae) from the gills of Argyrops spinifer (Forsskål) (Teleostei: Sparidae) from the Sea of Oman. Parasit Vectors 6:170. doi:10.1186/1756-3305-6-170 